\title{
BMJ Open Impact of non-communicable disease multimorbidity on health service use, catastrophic health expenditure and productivity loss in Indonesia: a population-based panel data analysis study
}

Tiara Marthias (D) ,1,2 Kanya Anindya (D) , ${ }^{1}$ Nawi Ng, ${ }^{3}$ Barbara McPake, ${ }^{1}$ Rifat Atun, ${ }^{4}$ Hafiz Arfyanto, ${ }^{5}$ Emily SG Hulse, ${ }^{6}$ Yang Zhao, ${ }^{7,8}$ Hafizah Jusril (D) , ${ }^{9}$ Tianxin Pan, ${ }^{6}$ Marie Ishida, ${ }^{1}$ John Tayu Lee (D) ${ }^{1,10}$

To cite: Marthias T, Anindya K, $\mathrm{Ng} \mathrm{N}$, et al. Impact of noncommunicable disease multimorbidity on health service use, catastrophic health expenditure and productivity loss in Indonesia: a population-based panel data analysis study. BMJ Open 2021;11:e041870. doi:10.1136/ bmjopen-2020-041870

- Prepublication history and additional materials for this paper is available online. To view these files, please visit the journal online (http://dx.doi. org/10.1136/bmjopen-2020041870).

TM and KA are joint first authors.

Received 19 June 2020 Revised 21 January 2021 Accepted 28 January 2021

A) Check for updates

(c) Author(s) (or their employer(s)) 2021. Re-use permitted under CC BY-NC. No commercial re-use. See rights and permissions. Published by BMJ.

For numbered affiliations see end of article.

Correspondence to Kanya Anindya; kanindya@student.unimelb. edu.au

\section{ABSTRACT}

Objectives To examine non-communicable diseases (NCDs) multimorbidity level and its relation to households' socioeconomic characteristics, health service use, catastrophic health expenditures and productivity loss. Design This study used panel data of the Indonesian Family Life Survey conducted in 2007 (Wave 4) and 2014 (Wave 5).

Setting The original sampling frame was based on 13 out of 27 provinces in 1993, representing $83 \%$ of the Indonesian population.

Participants We included respondents aged 50 years and above in 2007, excluding those who did not participate in both Waves 4 and 5 . The total number of participants in this study are 3678 respondents.

Primary outcome measures We examined three main outcomes; health service use (outpatient and inpatient care), financial burden (catastrophic health expenditure) and productivity loss (labour participation, days primary activity missed, days confined in bed). We applied multilevel mixed-effects regression models to assess the associations between NCD multimorbidity and outcome variables,

Results Women were more likely to have NCD multimorbidity than men and the prevalence of NCD multimorbidity increased with higher socioeconomic status. NCD multimorbidity was associated with a higher number of outpatient visits (compared with those without NCD, incidence rate ratio (IRR) $4.25,95 \% \mathrm{Cl} 3.33$ to 5.42 for individuals with $>3$ NCDs) and inpatient visits (IRR $3.68,95 \% \mathrm{Cl} 2.21$ to 6.12 for individuals with $>3$ NCDs). NCD multimorbidity was also associated with a greater likelihood of experiencing catastrophic health expenditure (for $>3$ NCDs, adjusted OR (aOR) 1.69, 95\% Cl 1.02 to 2.81) and lower participation in the labour force (aOR 0.23 , $95 \% \mathrm{Cl} 0.16$ to 0.33 ) compared with no NCD.

Conclusions NCD multimorbidity is associated with substantial direct and indirect costs to individuals, households and the wider society. Our study highlights the importance of preparing health systems for addressing
Strengths and limitations of this study

To our knowledge, our study provides the first comprehensive analysis using the single largest longitudinal survey in Indonesia, which examined the impact of multimorbidity on health service use, catastrophic health expenditure and productivity loss.

- This study applied multilevel mixed-effects regression models to examine factors associated with multimorbidity and its relationship to the outcome variables, while taking into account the hierarchical (nested) nature of the dataset.

- Our findings should be interpreted with caution since the assessment of non-communicable diseases was mostly based on self-reporting, which may not capture the true prevalence rate.

- Despite the fifth waves of Indonesian Family Life Survey dataset was conducted between 2014 and 2015 , the longitudinal design of the survey is extremely useful for measuring the impact of chronic diseases, accounting for within-individual variations over-time.

the burden of multimorbidity in low-income and middleincome countries.

\section{INTRODUCTION}

Non-communicable diseases (NCDs) continue to be the leading cause of global burden of diseases, with $78 \%$ of NCD-related mortality concentrated in low/middleincome countries (LMICs). ${ }^{1}$ The current COVID-19 pandemic highlights that the presence of NCDs can increase the fatality risk of a communicable disease. ${ }^{2}$ Indonesia, the third most populous country among LMICs (after China and India) with a population of 270 
million, has seen rapid demographic and epidemiological transitions over the last few decades. The threat of NCDs is expected to rise with the ageing population (population aged 65 or above), which is projected to account for a quarter of the population by $2070 .{ }^{3}$ Concurrently, the prevalence of NCD multimorbidity, defined as the presence of two or more NCDs, is expected to rise rapidly in many LMICs, as both life expectancy and exposure to risk factors increase. ${ }^{4}$ Indonesia has started recognising the burden of NCDs due to its substantial contribution to the top causes of death and disability-adjusted life years. ${ }^{5}$ However, current Indonesia health programmes remain limited to curative services, focusing on single chronic disease as opposed to assessing and mitigating the impact of multimorbidity on the individual, health system and wider society.

The growing burden of multimorbidity in LMICs was highlighted in the United Nations High-Level Meetings on NCDs in 2011, 2014 and 2018. ${ }^{6}$ LMICs typically have low levels of government expenditure for health and inadequate health insurance coverage, which often results in higher levels of out-of-pocket expenditure (OOPE) and risk of impoverishing patients with chronic health conditions. ${ }^{78}$ The economic burden of multimorbidity is further compounded by the fact that multiple healthcare specialists typically manage multimorbid patients in LMICs. ${ }^{9}$ This leads to inefficiencies with numerous different hospital visits, polypharmacy and suboptimal disease management. ${ }^{910}$

While the Indonesian health system is mainly funded by the government, it only spends around $2 \%$ of its Gross Domestic Product (GDP) on health, which is significantly lower than other LMICs with comparable income level. ${ }^{11}$ Approximately half of all health spending is covered by the public sector and one-third comes from OOP payment. ${ }^{12}$ While the primary healthcare (PHC) centres are designed as gatekeepers for primary prevention for NCDs, studies have found limited capacity of PHC in proper management of NCDs. ${ }^{13-15}$ There is also high public funding allocations to curative services at the hospital-level, ${ }^{16}$ with limited investment in preventive and promotive health services. ${ }^{12}$ Further, the poor and those living in limited-resource regions have generally lower hospital utilisation due to geographical barriers and high transportation costs. ${ }^{17} 18$ Low overall government health spending, coupled with limited investment in PHC and the high burden of NCDs may further increase the high OOPE in Indonesia and inequitable access to care. ${ }^{5}$

The Indonesian national health insurance programme expansion in 2014 was designed to achieve universal coverage by 2019. ${ }^{19}$ However, as of August 2020, the insurance coverage was only at $85.5 \%,{ }^{20}$ leaving around 40 million people remained uncovered. Furthermore, the insurance programme has been in funding deficit since its inception and recent studies identified that it may not be financially sustainable. ${ }^{12}$ Further, NCDs were responsible for around $60 \%$ of total spending of the insurance programme. Therefore, addressing NCDs through preventive and promotive programmes is pertinent to strengthen the Indonesian health system and the sustainability of its health insurance programme.

Evidence from high-income countries (HICs) has found that apart from the negative impact on health outcomes, multimorbidity imposes substantial economic costs on individuals and households. This is because patients with multimorbidity incur large medical expenditures and are more likely to be absent from work. ${ }^{81}{ }^{22}$ However, there is no previous study in Indonesia that has examined the economic burden of NCD multimorbidity, as earlier studies have focused on the burden of a single NCD. ${ }^{23}$ Results from this study may inform health systems reform across the region and be applicable to similar LMICs. We present the first study that uses longitudinal data to examine NCD multimorbidity levels, and their relationship to households' socioeconomic characteristics, health service use, catastrophic health expenditures and productivity loss.

\section{METHODS}

\section{Sample and data}

We used panel data from two waves of the Indonesian Family Life Survey (IFLS) conducted in 2007 (Wave 4) and 2014 (Wave 5). IFLS is an ongoing longitudinal survey that started in 1993 with four subsequent rounds of data collection (1997/1998, 2000, 2007/2008 and 2014/2015). The original sample was based on 13 out of 27 provinces in 1993, representing $83 \%$ of the population. Wave 5 was conducted between September 2014 and March 2015, with 76\% re-contact rate from the main respondents of Wave 1 . The dataset contains information at the individual-level and household-level, including sociodemographic characteristics, healthcare utilisation and expenditure, and labour participation. The objectives and methods of the IFLS are detailed elsewhere. ${ }^{24} 25$ This study included respondents aged 50 years and above in 2007 who participated in both Waves 4 and 5, and excluded those with missing values for the study variable. Our final sample is 3678 respondents and a sample flowchart is presented in online supplemental figure S1.

\section{Variables}

\section{Multimorbidity}

Our main variable of interest was NCD multimorbidity. Fourteen types of NCDs were included in Wave 5, but only 10 NCDs in Wave 4 . For consistency, our main analysis used 10 NCDs that were available in both waves, as the following: hypertension, diabetes, asthma, heart attack/coronary heart diseases, liver disease, stroke, cancer, arthritis/rheumatism, hypercholesterolaemia and depression/mental illness. The four NCDs that were only included in Wave 5 were: prostate diseases, kidney diseases (excluding malignancy), digestive diseases and memory-related diseases.

NCD status was either identified through self-reporting or physical examination. In the self-report section, 
respondents who answered affirmatively to the question, 'Has a doctor/paramedic/nurse/midwife ever told you that you had any of these conditions?', were defined as reporting an NCD. For hypertension and hypercholesterolaemia, the diagnoses were confirmed through a physical examination conducted by trained nurses, that is, blood pressure and total cholesterol levels. All IFLS respondents aged 15 years and older had their blood pressure recorded three times on alternate arms using Omron self-inflating sphygmomanometers by trained nurses. ${ }^{2425}$ In our analysis, a respondent was categorised as having hypertension if the mean measurement of systolic blood pressure was $\geq 140 \mathrm{~mm} \mathrm{Hg}$ and/or mean diastolic blood pressure was $\geq 90 \mathrm{~mm} \mathrm{Hg}$ or the respondent selfreported having been diagnosed with hypertension. ${ }^{26} \mathrm{We}$ also included hypercholesterolaemia, defined as total blood cholesterol value $\geq 240 \mathrm{mg} / \mathrm{dL}$, as morbidity. ${ }^{27}$ It is important to note that different measurements of hypercholesterolaemia were used in Wave 4 and 5. Blood test for total cholesterol was performed in Wave 4 as opposed to self-reporting of hypercholesterolaemia in Wave 5.

A total of 10 NCDs were used to quantify the number of NCDs $(0,1,2,3$ or more) and respondents with two or more NCDs were categorised as having multimorbidity ( 0 or 1 ). Previous studies have typically considered hypertension, obesity and hypercholesterolaemia as risk factors of NCDs and their inclusion in the multimorbidity clustering remains inconsistent. ${ }^{23} 28$ Therefore, in the sensitivity analysis, we included obesity, defined as having body mass index $\geq 25 \mathrm{~kg} / \mathrm{m}^{2}$, in the clustering of multimorbidity. ${ }^{29}$ All statistical analyses were conducted using STATA V.14.2 SE.

\section{Outcome variables}

The three main outcomes are: health service use and financial burden as the direct cost and productivity loss as the indirect cost of multimorbidity. Respondents were asked about the number of outpatient visits (in the last 4 weeks) and inpatient visits (in the last 12 months) and OOPE. The data on OOPE was also collected with 4 weeks and 12 months recall period for outpatient and inpatient visits, respectively. We calculated the total annual OOPE by multiplying OOPE for outpatient visits with 13 (as the reference period of outpatient expenditure in the IFLS is 4 weeks and a year consists of 52 weeks), and added OOPE for inpatient visits. The total OOPE reflects all costs associated with outpatient or inpatient visits, including medication, medical consultation and laboratory tests.

Catastrophic health expenditure occurs when OOPE exceeds certain thresholds of a household's expenditure. The thresholds used in this study were $10 \%$ and $25 \%$ of total household expenditure (as proposed by the sustainable development goal 3 targets), and the WHO's recommendation at $40 \%$ of household's capacity to pay. Capacity to pay is defined as the household's ability to pay for other expenses, including medical costs, after having household subsistence needs met. ${ }^{30}$ Household subsistence needs are proxied by the household non-food expenditure variable. Catastrophic health expenditure $\left(\right.$ cata $\left._{h}\right)$ occurrence is expressed as follows:

cata $_{h}=1$ if $\frac{H S_{h}}{T H E_{h}}$ or $\frac{H S_{h}}{C T P_{h}}>z$, and otherwise is zero.

Where $H S_{h}$ is the total OOPE for health, $T H E_{h}$ is the total household expenditure, $C T P_{h}$ is capacity to pay and $z$ is the threshold of capacity to pay. In using the proportion of total OOPE for health to total household expenditure (THE), the threshold $z$ was set at $10 \%$ and $25 \%$. Further, in using the proportion of OOPE for health to capacity to pay, the threshold $z$ was set at $40 \%$. All monetary values were adjusted for inflation and converted to 2014 International Dollars. ${ }^{31}$

Productivity loss was assessed based on: (1) labour participation; (2) the number of days of primary activity missed due to poor health and (3) number of days confined to bed. Labour participation status was defined as the respondent's employment status at the time of the survey. The number of days of primary daily activity missed and days confined to bed were included in the health conditions section of the survey, with a 4-week recall period.

\section{Covariates}

Sociodemographic factors included were: sex, age groups (50-60, 61-70, above 70 years), marital status (currently and not currently married), education (no education, primary, junior high school, senior high school, tertiary), ethnicity (Javanese, Sundanese, others), coverage of health insurance (no, yes), type of work (unemployed, casual, self-employed, government/private) and respondents' economic status (per capita expenditure for consumption). The economic status was categorised into quintiles: Q1 (lowest) to Q5 (highest). We also included residency (rural, urban), region of residency (Java-Bali, Sumatra, Nusa Tenggara, Kalimantan, Sulawesi) and period (using wave 2007 as the reference group) as covariates. Detailed definitions and categorisations are available in online supplemental table S1. It should be noted that IFLS did not include the eastern regions which are considered to be underdeveloped.

\section{Statistical analysis}

We described the patterns of multimorbidity across different population subgroups and presented the weighted percentages with $95 \%$ CI. Taking into account the hierarchical (nested) nature of the dataset (ie, observations nested within individuals, and individuals nested within households and districts), ${ }^{32}$ a multilevel level model approach was used to examine factors associated with multimorbidity and its relation to the outcome variables. Multilevel negative binomial regression models were performed to examine the association between multimorbidity and the numbers of outpatient visits and days in the hospital. We used negative binomial models instead of Poisson models due to the over-dispersion of the count data variable. We applied multilevel logistic regression models to observe binary outcome variables and calculated the intra-class correlation coefficients 
(ICC). The multilevel analyses were conducted using unweighted data, since rather than deriving nationally representative estimates, our aim was on testing the association between multimorbidity and the outcomes and examine the mixed effects. ${ }^{33}$ We conducted a robustness check to investigate the association between multimorbidity and costs using the 2014 cross-sectional dataset, that contains information for four additional NCDs than the 2007 IFLS.

\section{Patient and public involvement}

Neither patients nor the public were involved in this secondary data analysis.

\section{RESULTS}

\section{Descriptive statistics}

Table 1 and online supplemental table S2 presents the respondents' characteristics by multimorbidity status in 2007 and 2014. The median age in 2007 was 58 years (IQR 54-65), 53.9\% were women, $74.4 \%$ were married, $16.5 \%$ had at least secondary education level or above and only $25.5 \%$ had health insurance coverage. In 2014, the median age was 65 years (IQR 60-72), and health insurance coverage increased to $42.8 \%$.

A similar prevalence of NCD multimorbidity was observed between 2007 (21.0\%, 95\% CI 19.6 to 22.6) and $2014(22.0 \%, 95 \%$ CI 20.6 to 23.6). The prevalence of multimorbidity increased with rising socioeconomic status. For example, in 2014, the prevalence increased from $18.0 \%$ (95\% CI 16.9 to 20.7 ) to $41.2 \%$ (95\% CI 31.6 to 51.6) between respondents with no education and those with tertiary education. Similarly, the prevalence increased from $13.5 \%$ (95\% CI 11.1 to 16.2 ) to $36.2 \%$ (95\% CI 32.2 to 40.5$)$ between the lowest and highest wealth quintiles. The trend of increasing multimorbidity was observed for all age groups, shown in figure 1, where the fifth and fourth wealth quintiles had a higher prevalence of NCD multimorbidity than the lower quintiles. The prevalence of multimorbidity by level of education is available in online supplemental figure S2.

The regression results show that NCD multimorbidity was more likely among those with higher socioeconomic status (table 1). Respondents in the highest wealth quintile were more likely to report NCD multimorbidity, compared with those in the lowest quintile (adjusted OR (aOR) 2.22, $95 \%$ CI 1.72 to 2.86). Compared with those with lower educational attainment, respondents with higher educational attainment were more likely to experience NCD multimorbidity (aOR $1.54,95 \%$ CI 1.01 to 2.34 for tertiary level completed). Additionally, the prevalence of multimorbidity was higher in women than men (aOR 1.74, 95\% CI 1.46 to 2.08) and those living in urban areas (aOR 1.41, 95\% CI 1.19 to 1.67). The ICC shows that above $53 \%(1-[0.34+0.13])$ of the variance can be ascribed to between-individual level differences (online supplemental table S3).

\section{Multimorbidity and health service use}

The probability of using outpatient and inpatient care and the number of visits increased with more NCD diagnoses (tables 2 and 3). Respondents with a single NCD were 1.35 times more likely (95\% CI 1.15 to 1.58 ) to have experienced an outpatient visit in the past 4 weeks compared with those without an NCD. The odds of an outpatient visit increased to 4.66 times (95\% CI 3.55 to 6.11), while the incidence rate increased by 4.25 times (95\% CI 3.33 to 5.42) in those with three or more NCDs. Furthermore, the incidence of inpatient visits was 3.68 times (95\% CI 2.21 to 6.12) higher in those with three or more NCDs, compared with those without an NCD.

We reported the results of ICC in online supplemental table S3. We found that $14 \%$ and $11 \%$ of the variance in the outpatient visit were attributable to the differences within-individuals and households, respectively. Betweenindividual variation accounted for the largest variation, where it explained $75 \%(1-[0.14+0.11])$ and $65 \%(1-$ $[0.25+0.12])$ of outpatient and inpatient visit, respectively. No influence of district-level variables was found $(\mathrm{ICC}=0)$.

\section{Multimorbidity and financial burden}

Table 2 presents the mean OOPE based on 2014 IFLS. The mean OOPE for outpatient care incurred by respondents during the last 4 weeks increased from INT $\$ 17$ in those without any NCDs to INT $\$ 60$ in those with three or more NCDs in 2014. Similarly, for inpatient visits, having three or more NCDs resulted in a higher mean OOPE of $\$ 762$ ( $\mathrm{SD} \pm \$ 1421)$ compared with $\$ 566$ ( $\mathrm{SD} \pm \$ 1880$ ) for those without any NCDs. The total annual OOPE also increased from $\$ 295$ ( $\mathrm{SD} \pm \$ 977$ ), among those without any NCDs, to $\$ 968$ (SD $\pm \$ 4313$ ) among those with three or more NCDs. Table 2 also presents the proportion of respondents with catastrophic health expenditure using different thresholds. The results using $10 \%$ and $25 \%$ of THE, and $40 \%$ of non-food consumption thresholds found that households with more than two NCDs had a higher proportion of catastrophic health expenditure compared with households without any member having any NCDs.

Table 4 presents the logistic regression results for the proportion of respondents who experienced catastrophic health expenditure using different thresholds. At 10\% of THE as the threshold, having two NCDs increases the odds of catastrophic health expenditure to 1.58 times (95\% CI 1.06 to 2.35 ), compared with having no NCD. These odds increased to 1.69 times for those having three NCDs or more (95\% CI 1.02 to 2.81). At $25 \%$ and $40 \%$ thresholds, we found no significant association between the number of NCD and the incidence of catastrophic health expenditure.

\section{Multimorbidity and productivity loss}

More NCDs diagnoses were associated with greater productivity loss (tables 2 and 5). For example, among those aged 50-60 years old, only $49.8 \%$ (95\% CI 36.7 to 62.9) of respondents with three or more NCDs were 
Table 1 Sample characteristics and factors associated with multimorbidity

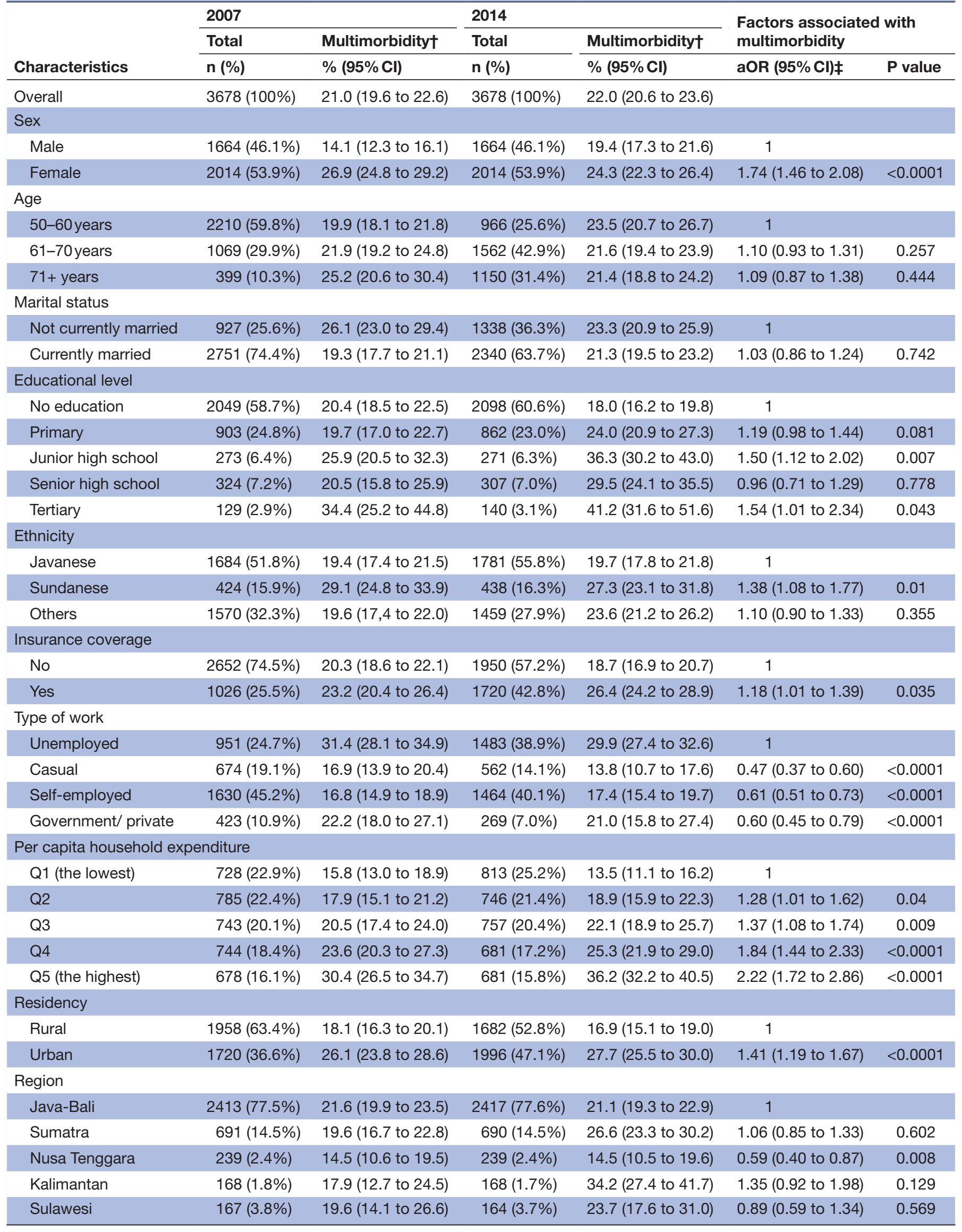


Table 1 Continued

\begin{tabular}{|c|c|c|c|c|c|}
\hline \multirow[b]{3}{*}{ Characteristics } & \multicolumn{2}{|l|}{2007} & \multicolumn{2}{|l|}{2014} & \multirow{2}{*}{$\begin{array}{l}\text { Factors associated with } \\
\text { multimorbidity }\end{array}$} \\
\hline & Total & Multimorbidity $†$ & Total & Multimorbidity† & \\
\hline & n (\%) & $\%(95 \% \mathrm{Cl})$ & n (\%) & $\%(95 \% \mathrm{Cl})$ & aOR $(95 \%$ Cl)‡ \\
\hline
\end{tabular}

*Values are unweighted counts and weighted percentages unless otherwise indicated.

tWe defined multimorbidity if the respondents reported that they had two or more chronic conditions related to non-communicable diseases. Chronic diseases included: hypertension, diabetes, asthma, heart attack/coronary heart diseases, liver disease, stroke, cancer, arthritis/rheumatism, hypercholesterolaemia and mental illness.

$\ddagger$ Adjusted odds ratio (aOR) was estimated using multilevel logistic regression model of 2007 and 2014 Indonesian Family Life Survey.

employed, compared with $84.3 \%$ (95\% CI 79.8 to 88.0 ) of respondents without NCD (table 2). The mean number of days of primary daily activity missed increased from 2.7 days ( $\mathrm{SD} \pm 6.0$ ), for those without any NCDs, to 10.1 days ( $\mathrm{SD} \pm 12.1)$ for those with three or more NCDs. The mean number of days confined to bed also increased among those with three or more NCDs.

Individuals diagnosed with three or more NCDs were 0.23 times less likely ( $95 \%$ CI 0.16 to 0.33 ) to be employed compared with those without NCD (table 5). Compared with those without NCD, being diagnosed with three or more NCDs were expected to have a higher incidence rate of missing days of primary activity (IRR 2.59, 95\% CI 1.97 to 3.41) as well as days confined in bed (IRR 2.64, $95 \%$ CI 1.60 to 4.36 ). We found that $48 \%$ of the variance in labour participation was due to within-individual variations, while between-individual variation accounted for $23 \%(1-[0.48+0.28+0.01])$ (online supplemental table S3).

\section{Robustness check}

Our robustness analysis using 2014 cross-sectional dataset that consists of 14 physical NCDs (online supplemental tables S4-S7) showed consistent results with our original findings. Higher household expenditure and higher

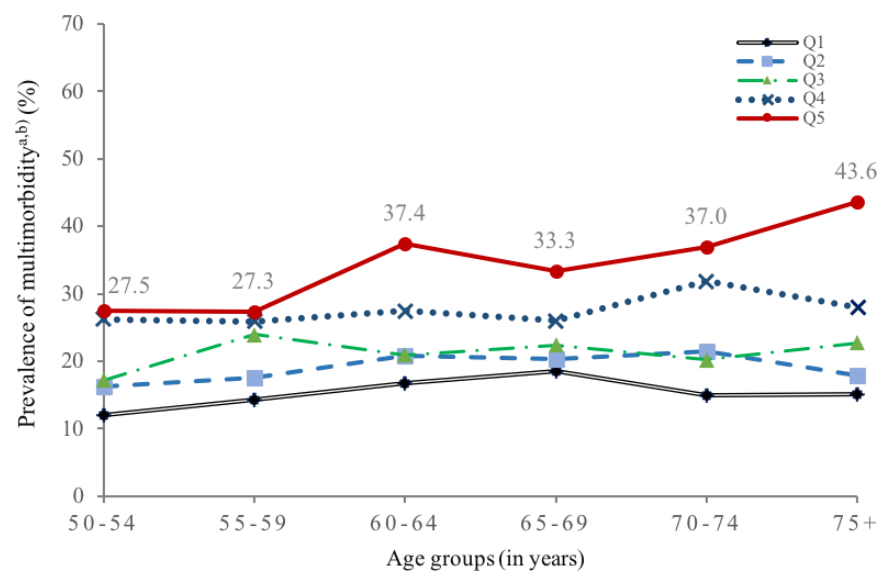

Figure 1 Prevalence of multimorbidity by age group and per

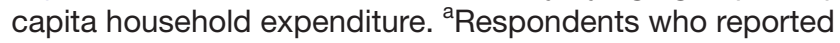
that they had two or more chronic conditions related to noncommunicable diseases. ${ }^{b}$ Pooled sample of Wave 4 and Wave 5. Q1-Q5 refer to household expenditure quintiles, where Q1 is the lowest and Q5 the highest household expenditure quintile. education were associated with a greater burden of multimorbidity. Multimorbidity was also associated with higher healthcare use, higher incidence of catastrophic health expenditures, and lower productivity. The association between multimorbidity and catastrophic health expenditure was more pronounced in the cross-sectional analysis. Our inclusion of obesity in the clustering of multimorbidity also yields consistent results (online supplemental tables S8-S10).

\section{DISCUSSION}

Our study provides the first comprehensive analysis of multimorbidity in Indonesia using the only large panel dataset in Indonesia. Our study reveals that almost one in four of our study population has at least two NCDs, with $6.5 \%$ having three or more in 2014. Our findings show a higher prevalence of multimorbidity in wealthier population groups. Multimorbidity was associated with a higher use of healthcare services, higher probability of catastrophic health expenditure and a reduction in productivity.

Analyses of socioeconomic gradients of NCDs in HICs routinely find negative socioeconomic gradients. However, this is not the case for LMICs, which have a more mixed pattern of the distribution of risk factors. ${ }^{34} 35$ Other studies find a similar pattern with diabetes and cardiovascular diseases in LMICs undergoing epidemiological transition. ${ }^{35}$ These conditions predominate in high-income quintiles in early stages of transition, which may explain our findings on the higher prevalence of NCD multimorbidity among more affluent population. We also found that obesity was more prevalent in wealthier quintiles. As obesity is associated with several NCDs (cardiovascular diseases, hypertension, stroke, cancer, arthritis and hypercholesterolaemia), ${ }^{36}$ this may explain our findings on socioeconomic gradients of NCDs. Further, our results on socioeconomic patterning of multimorbidity can be explained by the fact that higher-income and highereducational groups have better health literacy and access to healthcare services and thus, are more likely to have NCDs diagnosed than lower socio-income groups.

Our findings showing the association between having more NCDs and greater use of health services are in line with earlier studies from both HICs and LMICs. ${ }^{98} 87$ The presence of NCD multimorbidity was also associated with 


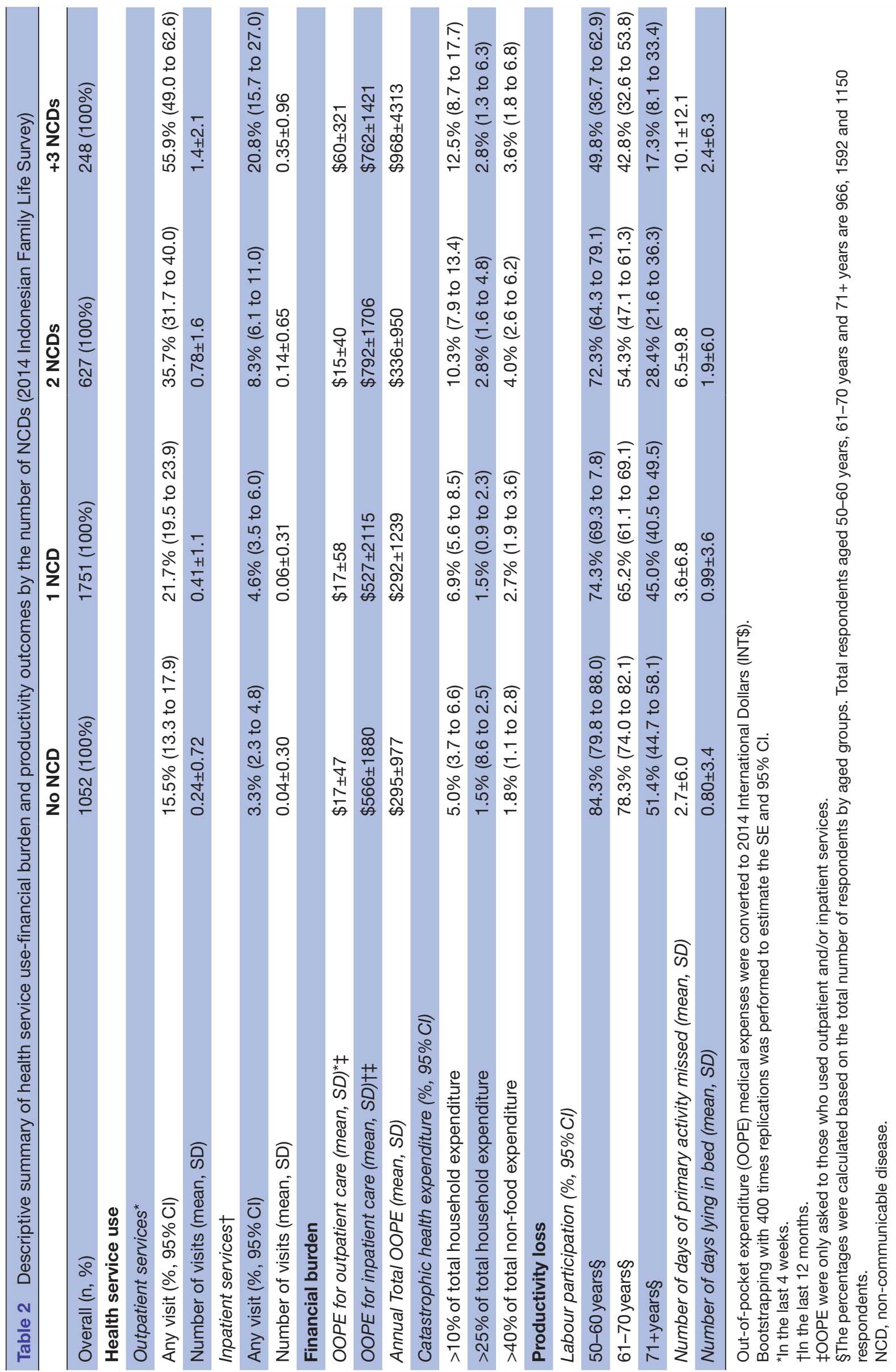


Table 3 The effect of multimorbidity on health service use

\begin{tabular}{|c|c|c|c|c|c|c|c|c|}
\hline \multirow{3}{*}{ Variables } & \multicolumn{8}{|c|}{ Health service use } \\
\hline & \multicolumn{4}{|l|}{ Outpatient } & \multicolumn{4}{|l|}{ Inpatient } \\
\hline & \multicolumn{2}{|l|}{ Any visit* } & \multicolumn{2}{|c|}{ Number of visits $†$} & \multicolumn{2}{|l|}{ Any visit* } & \multicolumn{2}{|c|}{ Number of visits $†$} \\
\hline \multicolumn{9}{|c|}{ Number of NCDs (ref. no NCD) } \\
\hline Single NCD & $\begin{array}{l}1.35(1.15 \text { to } \\
1.58)\end{array}$ & $<0.0001$ & $\begin{array}{l}1.45 \text { (1.24 to } \\
1.69)\end{array}$ & $<0.0001$ & $\begin{array}{l}1.07 \text { (0.78 to } \\
1.48)\end{array}$ & 0.671 & $\begin{array}{l}1.06 \text { (0.75 to } \\
1.50)\end{array}$ & 0.755 \\
\hline $\begin{array}{l}\text { Three or more } \\
\text { NCDs }\end{array}$ & $\begin{array}{l}4.66 \text { (3.55 to } \\
6.11)\end{array}$ & $<0.0001$ & $\begin{array}{l}4.25 \text { (3.33 to } \\
5.42)\end{array}$ & $<0.0001$ & $\begin{array}{l}3.69(2.35 \text { to } \\
5.79)\end{array}$ & $<0.0001$ & $\begin{array}{l}3.68(2.21 \text { to } \\
6.12)\end{array}$ & $<0.0001$ \\
\hline \multicolumn{9}{|l|}{ Period (ref. 2007) } \\
\hline \multicolumn{9}{|l|}{ Age (ref. 50-60 years) } \\
\hline $61-70$ years & $\begin{array}{l}1.01(0.86 \text { to } \\
1.18)\end{array}$ & 0.905 & $\begin{array}{l}1.00(0.87 \text { to } \\
1.16)\end{array}$ & 0.969 & $\begin{array}{l}1.07 \text { (0.78 to } \\
1.45)\end{array}$ & 0.677 & $\begin{array}{l}1.17(0.84 \text { to } \\
1.65)\end{array}$ & 0.351 \\
\hline $71+$ years & $\begin{array}{l}1.10(0.90 \text { to } \\
1.34)\end{array}$ & 0.351 & $\begin{array}{l}1.06 \text { (0.88 to } \\
1.27)\end{array}$ & 0.567 & $\begin{array}{l}1.49(1.03 \text { to } \\
2.15)\end{array}$ & 0.034 & $\begin{array}{l}1.66(1.11 \text { to } \\
2.49)\end{array}$ & 0.014 \\
\hline \multicolumn{9}{|c|}{ Marital status (ref. not married) } \\
\hline Currently married & $\begin{array}{l}1.14(0.97 \text { to } \\
1.34)\end{array}$ & 0.105 & $\begin{array}{l}1.15 \text { (0.99 to } \\
1.34)\end{array}$ & 0.069 & $\begin{array}{l}1.04(0.77 \text { to } \\
1.40)\end{array}$ & 0.815 & $\begin{array}{l}0.98 \text { (0.71 to } \\
1.37)\end{array}$ & 0.914 \\
\hline Tertiary & $\begin{array}{l}1.29(0.90 \text { to } \\
1.84)\end{array}$ & 0.167 & $\begin{array}{l}0.93 \text { (0.66 to } \\
1.32)\end{array}$ & 0.697 & $\begin{array}{l}0.98(0.53 \text { to } \\
1.80)\end{array}$ & 0.937 & $\begin{array}{l}0.85 \text { (0.42 to } \\
1.69)\end{array}$ & 0.640 \\
\hline \multicolumn{9}{|c|}{ Ethnicity (ref. Javanese) } \\
\hline Sundanese & $\begin{array}{l}0.92(0.74 \text { to } \\
1.14)\end{array}$ & 0.464 & $\begin{array}{l}0.95(0.77 \text { to } \\
1.16)\end{array}$ & 0.617 & $\begin{array}{l}0.90(0.61 \text { to } \\
1.34)\end{array}$ & 0.609 & $\begin{array}{l}1.14(0.75 \text { to } \\
1.76)\end{array}$ & 0.536 \\
\hline Others & $\begin{array}{l}1.06 \text { (0.89 to } \\
1.25)\end{array}$ & 0.525 & $\begin{array}{l}0.99(0.84 \text { to } \\
1.16)\end{array}$ & 0.877 & $\begin{array}{l}0.90(0.65 \text { to } \\
1.23)\end{array}$ & 0.495 & $\begin{array}{l}1.08(0.76 \text { to } \\
1.52)\end{array}$ & 0.676 \\
\hline \multicolumn{9}{|c|}{ Insurance coverage (ref. no) } \\
\hline Yes & $\begin{array}{l}1.48 \text { (1.28 to } \\
1.70)\end{array}$ & $<0.0001$ & $\begin{array}{l}1.51 \text { (1.32 to } \\
1.72)\end{array}$ & $<0.0001$ & $\begin{array}{l}1.90(1.45 \text { to } \\
2.50)\end{array}$ & $<0.0001$ & $\begin{array}{l}1.65 \text { (1.23 to } \\
2.21)\end{array}$ & 0.001 \\
\hline \multicolumn{9}{|c|}{ Type of work (ref. unemployed) } \\
\hline Casual & $\begin{array}{l}0.76(0.62 \text { to } \\
0.95)\end{array}$ & 0.014 & $\begin{array}{l}0.69(0.57 \text { to } \\
0.85)\end{array}$ & $<0.0001$ & $\begin{array}{l}0.49(0.31 \text { to } \\
0.78)\end{array}$ & 0.003 & $\begin{array}{l}0.44(0.27 \text { to } \\
0.73)\end{array}$ & 0.001 \\
\hline Self-employed & $\begin{array}{l}0.85 \text { (0.73 to } \\
1.00)\end{array}$ & 0.056 & $\begin{array}{l}0.82(0.70 \text { to } \\
0.95)\end{array}$ & 0.008 & $\begin{array}{l}0.60(0.44 \text { to } \\
0.82)\end{array}$ & 0.001 & $\begin{array}{l}0.60(0.43 \text { to } \\
0.83)\end{array}$ & 0.002 \\
\hline $\begin{array}{l}\text { Government/ } \\
\text { private }\end{array}$ & $\begin{array}{l}0.75 \text { (0.58 to } \\
0.96)\end{array}$ & 0.025 & $\begin{array}{l}0.72(0.57 \text { to } \\
0.92)\end{array}$ & 0.008 & $\begin{array}{l}0.63(0.39 \text { to } \\
1.04)\end{array}$ & 0.071 & $\begin{array}{l}0.77(0.46 \text { to } \\
1.31)\end{array}$ & 0.335 \\
\hline
\end{tabular}

Per capita household expenditure (ref. Q1) 


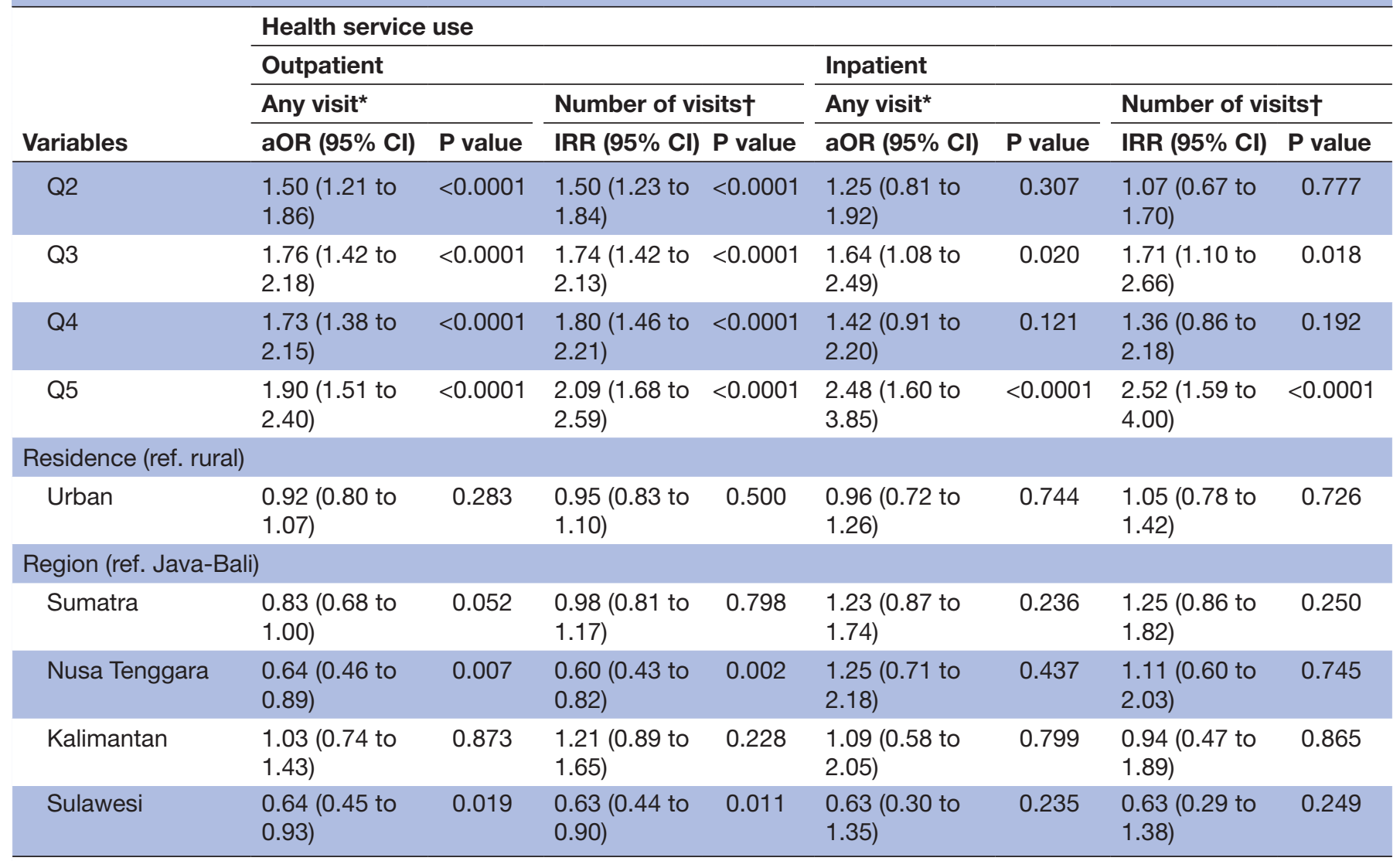

*Multilevel logistic regression model.

†Multilevel negative binomial regression model.

aOR, adjusted OR; IRR, incidence rate ratio; NCD, non-communicable disease.

a greater financial burden, which is mainly driven by higher healthcare use. These findings are consistent with earlier studies. ${ }^{10} 283738$ Based on a previous Indonesian study, four NCDs (hypertension, diabetes, heart problems and stroke) are the leading causes of mortality and were estimated to account for $12 \%$ of Indonesia's OOPE in 2020. ${ }^{22}$ Furthermore, the impoverishment effect of multimorbidity has been previously documented and is confirmed in our study. ${ }^{7212237}$

This study contributes to the growing evidence that multimorbidity has a substantial impact on disability and productivity. ${ }^{7922}$ Interventions that can help effectively prevent and manage multimorbidity have the potential for generating substantial returns on improved health, work productivity and social benefits. However, a large portion of the Indonesia government health expenditure is still geared towards curative care. ${ }^{5}$ Renewing the focus on health promotion and NCD prevention requires a strong PHC system. ${ }^{9}$ PHC is the entry point of a sustainable health system for the early detection of risk factors and initiation of a treatment-seeking pathway for patients with NCDs, and thus, plays a crucial role for NCD prevention and provision of long-term integrated care. Such policies would be in line with the current programme of the Ministry of Health in Indonesia to reorient public PHC to provide more promotive and preventive health services, such as through the implementation of Chronic Diseases Management Programme (Prolanis) in PHC. ${ }^{12}{ }^{39}$ However, the participation in this programme remains low due to the poor access to PHC facilities, especially in non-Java-Bali regions. Engaging the private sector, which makes up $60 \%$ of health facilities in Indonesia, is warranted to expand the coverage of NCDs promotive and prevention activities. ${ }^{40}$ Furthermore, the development of digital health solution and telehealth for NCDs prevention and control should be included in the national plan. ${ }^{41}$

Although most countries and international health organisations have recognised the importance of multimorbidity, ${ }^{42}$ most health policies and programmes still focus on single diseases, including in Indonesia. Therefore, the health systems need to shift from single-disease models to new financing methods and service delivery to more effectively manage multimorbidity. ${ }^{43}$ At the PHC level, this can be done through improved prevention and treatment of multimorbidity, underpinned by multidisciplinary teams led by general practitioners. ${ }^{42}$ There is also a need to strengthen the coordination of patient management between primary and secondary care. Similar to many LMICs and neighbouring countries in Asia, 
Table 4 The effect of multimorbidity on catastrophic expenditure

\section{Catastrophic health expenditure}

$10 \%$ of total household

expenditure*

Variables $\quad$ aOR (95\%

\begin{tabular}{|c|c|c|c|c|c|c|}
\hline Single NCD & $1.11(0.76$ to 1.62$)$ & 0.591 & $0.81(0.49$ to 1.34$)$ & 0.417 & $0.86(0.52$ to 1.43$)$ & 0.561 \\
\hline Two NCDs & 1.58 (1.06 to 2.35$)$ & 0.026 & 1.39 (0.79 to 2.45$)$ & 0.250 & 1.27 (0.69 to 2.35$)$ & 0.437 \\
\hline Three or more NCDs & 1.69 (1.02 to 2.81$)$ & 0.042 & 0.96 (0.40 to 2.34$)$ & 0.937 & 0.72 (0.27 to 1.89$)$ & 0.503 \\
\hline \multicolumn{7}{|l|}{ Period (ref. 2007) } \\
\hline 2014 & 1.42 (1.12 to 1.80$)$ & 0.003 & 1.27 (0.83 to 1.95$)$ & 0.271 & $1.18(0.77$ to 1.80$)$ & 0.442 \\
\hline \multicolumn{7}{|l|}{ Sex (ref. male) } \\
\hline Female & 0.89 (0.64 to 1.23$)$ & 0.480 & 0.90 (0.57 to 1.42$)$ & 0.645 & 0.83 (0.52 to 1.33 ) & 0.432 \\
\hline \multicolumn{7}{|l|}{ Age (ref. 50-60 years) } \\
\hline $61-70$ years & 1.15 (0.79 to 1.69$)$ & 0.461 & 1.46 (0.90 to 2.36$)$ & 0.125 & 1.43 (0.85 to 2.38$)$ & 0.175 \\
\hline $71+$ years & 1.13 (0.66 to 1.92$)$ & 0.663 & 1.01 (0.51 to 2.01$)$ & 0.975 & 1.24 (0.60 to 2.55$)$ & 0.563 \\
\hline
\end{tabular}

Marital status (ref. not married)

$\begin{array}{lllllll}\text { Currently married } & 1.59(1.22 \text { to } 2.09) & 0.001 & 1.68(0.98 \text { to } 2.87) & 0.060 & 1.83(1.01 \text { to } 3.33) & 0.047\end{array}$

Educational level (ref. no education)

\begin{tabular}{|c|c|c|c|c|c|c|}
\hline Primary & 0.96 (0.67 to 1.38$)$ & 0.841 & 0.90 (0.52 to 1.55$)$ & 0.708 & 0.85 (0.48 to 1.52$)$ & 0.589 \\
\hline Junior high school & 0.97 (0.64 to 1.47$)$ & 0.902 & 1.21 (0.58 to 2.55$)$ & 0.610 & 0.60 (0.25 to 1.48$)$ & 0.271 \\
\hline Senior high school & 0.93 (0.61 to 1.42$)$ & 0.735 & 1.22 (0.59 to 2.52$)$ & 0.595 & 0.81 (0.34 to 1.92$)$ & 0.627 \\
\hline Tertiary & $0.45(0.22$ to 0.90$)$ & 0.023 & 0.11 (0.01 to 0.94$)$ & 0.043 & 0.12 (0.02 to 0.84$)$ & 0.032 \\
\hline \multicolumn{7}{|l|}{$\begin{array}{l}\text { Ethnicity (ref. } \\
\text { Javanese) }\end{array}$} \\
\hline Sundanese & 0.87 (0.62 to 1.23$)$ & 0.433 & 1.80 (0.98 to 3.33$)$ & 0.060 & 1.14 (0.52 to 2.48$)$ & 0.748 \\
\hline Others & 0.76 (0.56 to 1.02$)$ & 0.065 & 1.01 (0.58 to 1.78$)$ & 0.959 & 0.56 (0.28 to 1.09$)$ & 0.088 \\
\hline \multicolumn{7}{|c|}{ Insurance coverage (ref. no) } \\
\hline Yes & 0.89 (0.67 to 1.20$)$ & 0.451 & 0.83 (0.53 to 1.31$)$ & 0.425 & 0.80 (0.49 to 1.32$)$ & 0.390 \\
\hline \multicolumn{7}{|c|}{ Type of work (ref. unemployed) } \\
\hline Casual & 0.59 (0.33 to 1.07$)$ & 0.082 & 0.58 (0.29 to 1.17$)$ & 0.128 & $0.41(0.20$ to 0.84$)$ & 0.015 \\
\hline Self-employed & $0.60(0.36$ to 1.01$)$ & 0.056 & 0.58 (0.35 to 0.96$)$ & 0.033 & $0.45(0.27$ to 0.76$)$ & 0.003 \\
\hline Government/private & $0.58(0.34$ to 1.02$)$ & 0.058 & 0.78 (0.35 to 1.70$)$ & 0.527 & $0.39(0.16$ to 0.95$)$ & 0.038 \\
\hline \multicolumn{7}{|c|}{ Per capita household expenditure (ref. Q1) } \\
\hline Q2 & $1.04(0.071$ to 1.52$)$ & 0.834 & $1.60(0.71$ to 3.57$)$ & 0.257 & 1.34 (0.62 to 2.90$)$ & 0.459 \\
\hline Q3 & 1.37 (0.97 to 1.95$)$ & 0.076 & $1.71(0.77$ to 3.80$)$ & 0.188 & 1.19 (0.54 to 2.61$)$ & 0.669 \\
\hline Q4 & $1.98(1.40$ to 2.81$)$ & $<0.0001$ & 3.11 (1.43 to 6.76$)$ & 0.004 & $2.73(1.23$ to 6.03$)$ & 0.013 \\
\hline Q5 & $3.13(2.28$ to 4.31$)$ & $<0.0001$ & 5.91 (2.72 to 12.85$)$ & $<0.0001$ & 8.45 (3.70 to 19.32$)$ & $<0.0001$ \\
\hline \multicolumn{7}{|l|}{ Residence (ref. rural) } \\
\hline Urban & $0.94(0.61$ to 1.45$)$ & 0.785 & 0.76 (0.46 to 1.24$)$ & 0.273 & $0.75(0.43$ to 1.31$)$ & 0.309 \\
\hline \multicolumn{7}{|l|}{ Region (ref. Java-Bali) } \\
\hline Sumatra & $0.78(0.56$ to 1.09$)$ & 0.146 & 0.73 (0.38 to 1.38$)$ & 0.328 & 1.08 (0.52 to 2.24$)$ & 0.846 \\
\hline Nusa Tenggara & $0.64(0.34$ to 1.21$)$ & 0.175 & $0.98(0.32$ to 2.99$)$ & 0.968 & 0.93 (0.22 to 3.83$)$ & 0.917 \\
\hline Kalimantan & 0.78 (0.39 to 1.52$)$ & 0.460 & 0.64 (0.19 to 2.24$)$ & 0.488 & 0.64 (0.15 to 2.77$)$ & 0.548 \\
\hline Sulawesi & 0.80 (0.43 to 1.48$)$ & 0.478 & 1.21 (0.41 to 3.57 ) & 0.724 & 1.31 (0.33 to 5.17$)$ & 0.701 \\
\hline
\end{tabular}

${ }^{*}$ Multilevel logistic regression model.

aOR, adjusted OR; NCD, non-communicable disease.

$25 \%$ of total household expenditure* $^{*}$ $40 \%$ of non-food expenditure* aOR $(95 \% \mathrm{Cl}) \quad$ P value

$P$ value aOR $(95 \% \mathrm{Cl})$

$P$ value aOR $(95 \% \mathrm{Cl})$ 
Table 5 The effect of multimorbidity on productivity loss

\begin{tabular}{|c|c|c|c|c|c|c|}
\hline \multirow[b]{3}{*}{ Variables } & \multicolumn{6}{|l|}{ Productivity loss } \\
\hline & \multicolumn{2}{|c|}{ Labour participation* } & \multicolumn{2}{|c|}{ Days primary activity missed $\dagger$} & \multicolumn{2}{|c|}{ Days confined in bed $†$} \\
\hline & aOR (95\% Cl) & $P$ value & IRR (95\% CI) & $P$ value & IRR (95\% Cl) & $P$ value \\
\hline Single NCD & 0.65 (0.54 to 0.79$)$ & $<0.0001$ & 1.25 (1.08 to 1.43$)$ & 0.002 & 1.09 (0.84 to 1.43$)$ & 0.509 \\
\hline Two NCDs & 0.45 (0.35 to 0.57$)$ & $<0.0001$ & 1.90 (1.58 to 2.29$)$ & $<0.0001$ & 1.87 (1.33 to 2.61$)$ & $<0.0001$ \\
\hline 2014 & 0.69 (0.59 to 0.81$)$ & $<0.0001$ & 1.66 (1.46 to 1.88$)$ & $<0.0001$ & 1.79 (1.40 to 2.29$)$ & $<0.0001$ \\
\hline \multicolumn{7}{|l|}{ Sex (ref. male) } \\
\hline Female & $0.21(0.17$ to 0.26$)$ & $<0.0001$ & 0.99 (0.86 to 1.14$)$ & 0.912 & $0.92(0.70$ to 1.21$)$ & 0.567 \\
\hline \multicolumn{7}{|l|}{ Age (ref. $50-60$ years) } \\
\hline Currently married & 1.51 (1.23 to 1.84$)$ & $<0.0001$ & $1.13(0.98$ to 1.31$)$ & 0.089 & $0.88(0.67$ to 1.17$)$ & 0.395 \\
\hline \multicolumn{7}{|c|}{ Educational level (ref. no education) } \\
\hline Primary & $0.89(0.71$ to 1.11$)$ & 0.305 & 0.92 (0.79 to 1.07$)$ & 0.263 & $1.00(0.75$ to 1.33$)$ & 0.999 \\
\hline Junior high school & 0.41 (0.29 to 0.57$)$ & $<0.0001$ & $0.94(0.74$ to 1.20$)$ & 0.631 & 0.87 (0.54 to 1.40$)$ & 0.570 \\
\hline Senior high school & 0.41 (0.29 to 0.58$)$ & $<0.0001$ & 0.68 (0.53 to 0.87$)$ & 0.002 & 0.81 (0.51 to 1.28$)$ & 0.362 \\
\hline Tertiary & 0.51 (0.31 to 0.82$)$ & 0.006 & 0.54 (0.38 to 0.78$)$ & 0.001 & 0.37 (0.18 to 0.78$)$ & 0.009 \\
\hline \multicolumn{7}{|l|}{ Ethnicity (ref. Javanese) } \\
\hline Sundanese & 0.50 (0.37 to 0.67$)$ & $<0.0001$ & 1.35 (1.11 to 1.65$)$ & 0.003 & 1.28 (0.89 to 1.85$)$ & 0.179 \\
\hline Others & 0.77 (0.61 to 0.98$)$ & 0.033 & 1.11 (0.95 to 1.30$)$ & 0.188 & $1.12(0.84$ to 1.49$)$ & 0.436 \\
\hline \multicolumn{7}{|c|}{ Insurance coverage (ref. no) } \\
\hline \multicolumn{7}{|c|}{ Type of work (ref. unemployed) } \\
\hline \multicolumn{7}{|c|}{ Per capita household expenditure (ref. Q1) } \\
\hline Q2 & $1.37(1.08$ to 1.75$)$ & 0.011 & $1.03(0.86$ to 1.23$)$ & 0.744 & $1.05(0.74$ to 1.49$)$ & 0.769 \\
\hline Q3 & 1.33 (1.03 to 1.71$)$ & 0.028 & 1.15 (0.96 to 1.38$)$ & 0.130 & 1.06 (0.75 to 1.50$)$ & 0.737 \\
\hline Q4 & $1.12(0.87$ to 1.46$)$ & 0.379 & 1.05 (0.87 to 1.27$)$ & 0.627 & $1.02(0.71$ to 1.46$)$ & 0.914 \\
\hline Q5 & 1.34 (1.01 to 1.77$)$ & 0.043 & 1.29 (1.05 to 1.58$)$ & 0.015 & 0.92 (0.63 to 1.35$)$ & 0.668 \\
\hline \multicolumn{7}{|l|}{ Residence (ref. Rural) } \\
\hline Urban & 0.44 (0.35 to 0.54$)$ & $<0.0001$ & 0.93 (0.81 to 1.07$)$ & 0.296 & 0.70 (0.54 to 0.89$)$ & 0.004 \\
\hline \multicolumn{7}{|l|}{ Region (ref. Java-Bali) } \\
\hline Sumatra & 0.95 (0.73 to 1.25$)$ & 0.735 & $1.13(0.94$ to 1. to 36$)$ & 0.194 & 1.01 (0.73 to 1.40$)$ & 0.956 \\
\hline Nusa Tenggara & 0.74 (0.48 to 1.14$)$ & 0.177 & 0.90 (0.68 to 1.20$)$ & 0.472 & 1.14 (0.67 to 1.93$)$ & 0.638 \\
\hline Kalimantan & 1.21 (0.75 to 1.94$)$ & 0.440 & 0.90 (0.67 to 1.22$)$ & 0.511 & 0.89 (0.51 to 1.57$)$ & 0.688 \\
\hline Sulawesi & 0.39 (0.24 to 0.62$)$ & $<0.0001$ & 0.99 (0.72 to 1.36$)$ & 0.948 & 0.94 (0.53 to 1.69$)$ & 0.845 \\
\hline
\end{tabular}

*Multilevel logistic regression model.

†Multilevel negative binomial regression model.

aOR, adjusted OR; IRR, incidence rate ratio; NCD, non-communicable disease.

healthcare delivery in Indonesia remains fragmented and hospital-centred, with little coordination among healthcare providers across different tiers of the system. ${ }^{45}$
Furthermore, under the current national health insurance scheme, the hospital reimbursement system that uses case-based groups has created significant gaps between 
reimbursable costs and actual hospital expenses. ${ }^{46}$ The reimbursement system, which is mainly based on primary diagnosis, limits the hospital's capacity and willingness to treat complicated cases such as those with multimorbidity. ${ }^{47}$ Thus, while clinical guideline for single NCD still has a prominent role, it also important for LMICs to develop a clinical guideline for multimorbidity, along with payment systems that would ensure quality health services at both primary and secondary levels of care for patients with multimorbidity. ${ }^{90}$ It is also worth noting that Indonesia is still facing the double burden of infectious and chronic diseases. Therefore, multimorbidity care delivery model needs to pay attention to the management of NCDs alongside infectious diseases.

There are several limitations to our study. First, the IFLS-5 was conducted between 2014 and 2015, which may not be able to capture the current prevalence of multimorbidity in Indonesia. Despite this limitation, IFLS is the only longitudinal survey available in Indonesia that is useful to produce more accurate estimates compared with using a cross-sectional dataset (eg, the National Socioeconomic Survey). Second, our findings should be interpreted with caution since the assessment of NCDs was mostly based on self-reporting. This may cause misreporting of the true diagnoses and prevalence of multimorbidity. The health service use and OOPE were also based on self-reporting and may be prone to recall bias. ${ }^{48}$ The use of self-reported diagnoses limits our assessment of the actual severity of the diseases, which may vary across socioeconomic status. Future studies should consider using different datasets (such as clinical dataset from the hospital) and applying clinical metrics such as Charlson index, which could more objectively capture disease severity and predict the health outcomes. ${ }^{49}$ Third, the IFLS sample did not include eastern Indonesia. There is a need to extend the multimorbidity assessment to the remaining regions. Finally, this research intentionally focused on the older population due to a significantly higher burden of NCDs in this population group. Future research should use cohort data to follow patients over a more extended time period to examine the impact of multimorbidity and its effects in younger population groups in LMICs. ${ }^{22}$

\section{CONCLUSION}

Multimorbidity poses substantial costs to individuals, households, health system and the wider society in Indonesia, which has an increasingly ageing population. Policymakers and employers in Indonesia should carefully design and invest in targeted public health and workplace interventions at the individual and population level to avert the adverse health and economic consequences of NCD multimorbidity.

\section{Author affiliations}

${ }^{1}$ Nossal Institute for Global Health, The University of Melbourne, Melbourne, Victoria, Australia

${ }^{2}$ Department of Public Health, Faculty of Medicine, Public Health and Nursing, Universitas Gadjah Mada, Yogyakarta, Indonesia
${ }^{3}$ School of Public Health and Community Medicine, Institution of Medicine, Sahlgrenska Academy, University of Gothenburg, Gothenburg, Sweden ${ }^{4}$ Department of Global Health and Population, Harvard T H Chan School of Public Health, Harvard University, Boston, Massachusetts, USA

${ }^{5}$ SMERU Research Institute, Jakarta, Indonesia

${ }^{6}$ Centre for Health Policy, School of Population and Global Health, The University of Melbourne, Melbourne, Victoria, Australia

${ }^{7}$ The George Institute for Global Health, Peking University Health Science Center, Beijing, China

${ }^{8}$ WHO Collaborating Centre on Implementation Research for Prevention and Control of Noncommunicable Diseases, Melbourne, VIC, Australia

${ }^{9}$ Center for Health Research, Universitas Indonesia, Depok, Indonesia

${ }^{10}$ Department of Primary Care and Public Health, School of Public Health, Imperial College London, London, UK

Acknowledgements The authors of the paper express sincere gratitude to the RAND for providing access to the data. We acknowledge Nur Arna Sucianti from SurveyMeter, for guiding us with data merging.

Contributors The aim of the research was developed by TM, KA, JTL. The methodology development and analysis were conducted by TM, KA, HA, TP, JTL. EH assisted in drafting the discussion section and proofread all section. YZ, $\mathrm{HJ}, \mathrm{Ml}$ contributed to background and discussion section. NN, BM, RA, JTL provided critical input in revising the manuscript. All authors reviewed, edited and commented on multiple versions of the manuscript.

Funding The authors have not declared a specific grant for this research from any funding agency in the public, commercial or not-for-profit sectors.

Competing interests None declared.

Patient consent for publication Not required.

Ethics approval The IFLS has been approved by ethics review boards at RAND Corporation and Gadjah Mada University in Indonesia. Written informed consent was sought from all respondents prior to data collection. As this study used IFLS publicly available datasets that contain no personal identification of the respondents, no further ethical approval was sought.

Provenance and peer review Not commissioned; externally peer reviewed.

Data availability statement Data are available in a public, open access repository. The datasets are publicly accessible after registration (https://www.rand.org/wellbeing/social-and-behavioral-policy/data/FLS/IFLS/access.html).

Supplemental material This content has been supplied by the author(s). It has not been vetted by BMJ Publishing Group Limited (BMJ) and may not have been peer-reviewed. Any opinions or recommendations discussed are solely those of the author(s) and are not endorsed by BMJ. BMJ disclaims all liability and responsibility arising from any reliance placed on the content. Where the content includes any translated material, BMJ does not warrant the accuracy and reliability of the translations (including but not limited to local regulations, clinical guidelines, terminology, drug names and drug dosages), and is not responsible for any error and/or omissions arising from translation and adaptation or otherwise.

Open access This is an open access article distributed in accordance with the Creative Commons Attribution Non Commercial (CC BY-NC 4.0) license, which permits others to distribute, remix, adapt, build upon this work non-commercially, and license their derivative works on different terms, provided the original work is properly cited, appropriate credit is given, any changes made indicated, and the use is non-commercial. See: http://creativecommons.org/licenses/by-nc/4.0/.

\section{ORCID iDs}

Tiara Marthias http://orcid.org/0000-0001-8226-9473

Kanya Anindya http://orcid.org/0000-0001-6832-0412

Hafizah Jusril http://orcid.org/0000-0002-4748-8061

John Tayu Lee http://orcid.org/0000-0002-1551-4923

\section{REFERENCES}

1 World Health Organization. Noncommunicable diseases country profiles 2018, 2018. Available: https://apps.who.int/iris/handle/ 10665/274512 [Accessed 10 Oct 2019].

2 Zhang L, Sun W, Wang Y, et al. Clinical course and mortality of stroke patients with coronavirus disease 2019 in Wuhan, China. Stroke 2020;51:2674-82. 
3 United Nations, Department of Economic and Social Affairs, Population Division. World population prospects 2019. Online edn. UN DESA, 2019. https://population.un.org/wpp/Download/Standard/ Population/

4 Hussain MA, Huxley RR, Al Mamun A. Multimorbidity prevalence and pattern in Indonesian adults: an exploratory study using national survey data. BMJ Open 2015;5: 009810.

5 Mboi N, Murty Surbakti I, Trihandini I, et al. On the road to universa health care in Indonesia, 1990-2016: a systematic analysis for the global burden of disease study 2016. The Lancet 2018;392:581-91.

6 United Nations. Political declaration of the third high-level meeting of the general assembly on the prevention and control of noncommunicable diseases, 2018. Available: https://www.un.org/en/ga/ search/view_doc.asp?symbol=A/RES/73/2 [Accessed 8 Mar 2020].

7 Sum G, Hone T, Atun R, et al. Multimorbidity and out-of-pocket expenditure on medicines: a systematic review. BMJ Glob Health 2018;3:e000505.

8 Wang L, Si L, Cocker F, et al. A systematic review of cost-ofillness studies of multimorbidity. Appl Health Econ Health Policy 2018;16:15-29.

9 Barnett K, Mercer SW, Norbury M, et al. Epidemiology of multimorbidity and implications for health care, research, and medical education: a cross-sectional study. Lancet 2012;380:37-43.

10 Salisbury C. Multimorbidity: redesigning health care for people who use it. Lancet 2012;380:7-9.

11 World Bank Group. Indonesia Health Financing System Assessment : Spend More, Right and Better. Washington, DC: World Bank, 2016. https://openknowledge.worldbank.org/handle/10986/25363

12 Gani A, Budiharsana M. The consolidated report on Indonesia health sector review 2018. Jakarta, Indonesia: Bappenas, 2018.

13 Werdhani RA. Medical problem in Asia Pacific and ways to solve it: the roles of primary care/family physician (Indonesia Xperience). $J$ Family Med Prim Care 2019;8:1523-7.

14 Rokx C. New insights into the provision of health services in Indonesia: a health workforce study. World Bank Publications, 2010. http://documents1.worldbank.org/curated/en/799111468038325818/ pdf/538830PUB0Heal101OfficialOUse0Only1.pdf

15 Rajan VS, Patil A, Pambudi ES. Is Indonesia Ready to Serve? : An analysis of Indonesia's primary health care supply-side readiness. Washington, DC: World Bank Group: World Bank, 2018. http:// documents.worldbank.org/curated/en/484351538653658243/ Is-Indonesia-Ready-to-Serve-An-Analysis-of-Indonesia-s-PrimaryHealth-Care-Supply-Side-Readiness

16 Mahendradhata Y, Trisnantoro L, Dewi S. The Republic of Indonesia health system review. India: World Health Organization, 2017. https:// apps.who.int/iris/handle/10665/254716

17 Alatas V, Banerjee A, Hanna R, et al. Targeting the poor: evidence from a field experiment in Indonesia. Am Econ Rev 2012;102:1206-40.

18 Noerdin E. Transport, health services and budget allocation to address maternal mortality in rural Indonesia. Trans Commun Bulletin Asia Pacific 2014;84:1-14.

19 Agustina R, Dartanto T, Sitompul R, et al. Universal health coverage in Indonesia: concept, progress, and challenges. Lancet 2019;393:75-102.

20 BPJS Kesehatan. JKN coverage, 2020. Available: https://bpjskesehatan.go.id/bpjs/ [Accessed 1 Oct 2020].

21 Jaspers L, Colpani V, Chaker L, et al. The global impact of noncommunicable diseases on households and impoverishment: a systematic review. Eur J Epidemiol 2015;30:163-88.

22 Lee JT, Hamid F, Pati S, et al. Impact of noncommunicable disease multimorbidity on healthcare utilisation and out-of-pocket expenditures in middle-income countries: cross sectional analysis. PLoS One 2015;10:e0127199.

23 Finkelstein EA, Chay J, Bajpai S. The economic burden of selfreported and undiagnosed cardiovascular diseases and diabetes on Indonesian households. PLoS One 2014;9:e99572.

24 Strauss J, Witoelar F, Sikoki B. The fifth wave of the Indonesia family life survey: overview and field report. RAND Corporation 2016;1.

25 Strauss J, Witoelar F, Sikoki B. The fourth wave of the Indonesian family life survey (IFLS4): overview and field report. RAND Corporation 2009.

26 Chobanian AV, Bakris GL, Black HR, et al. The seventh report of the joint national committee on prevention, detection, evaluation, and treatment of high blood pressure: the JNC 7 report. JAMA 2003;289:2560-71.
27 Grundy SM, Cleeman JI, Merz CNB, et al. Implications of recent clinical trials for the national cholesterol education program adult treatment panel III guidelines. J Am Coll Cardiol 2004;44:720-32.

28 Hussain MA, Huxley RR, Al Mamun A. Multimorbidity prevalence and pattern in Indonesian adults: an exploratory study using national survey data. BMJ Open 2015;5:e009810.

29 World Health Organization. The Asia-Pacific perspective: redefining obesity and its treatment, 2000.

30 Xu K, Evans DB, Kawabata K, et al. Household catastrophic health expenditure: a multicountry analysis. Lancet 2003;362:111-7.

31 Organisation for Economic Co-operation and Development (OECD). Purchasing power parities (PPP). Available: https://data.oecd.org/ conversion/purchasing536 power-parities-ppp.htm [Accessed 10 Sep 2019].

32 Vaezghasemi $\mathrm{M}, \mathrm{Ng} \mathrm{N}$, Eriksson $\mathrm{M}$, et al. Households, the omitted level in contextual analysis: disentangling the relative influence of households and districts on the variation of BMl about two decades in Indonesia. Int J Equity Health 2016;15:102.

33 Lee ES, Forthofer RN. Analyzing complex survey data. Sage, 2006.

34 Hosseinpoor AR, Bergen N, Kunst A, et al. Socioeconomic inequalities in risk factors for non communicable diseases in lowincome and middle-income countries: results from the world health survey. BMC Public Health 2012;12:912.

35 Manne-Goehler J, Atun R, Stokes A, et al. Diabetes diagnosis and care in sub-Saharan Africa: pooled analysis of individual data from 12 countries. Lancet Diabetes Endocrinol 2016;4:903-12.

36 Field AE, Coakley EH, Must A, et al. Impact of overweight on the risk of developing common chronic diseases during a 10-year period. Arch Intern Med 2001;161:1581-6.

37 Wang HHX, Wang JJ, Wong SYS, et al. Epidemiology of multimorbidity in China and implications for the healthcare system: cross-sectional survey among 162,464 community household residents in southern China. BMC Med 2014:12:188

38 Mondor L, Maxwell CJ, Hogan DB, et al. Multimorbidity and healthcare utilization among home care clients with dementia in Ontario, Canada: a retrospective analysis of a population-based cohort. PLoS Med 2017;14:e1002249.

39 Deonisia A. Kemenkes akan memperkuat fungsi preventif DAN promotif melalui akreditasi Puskesmas. Available: https://kompas. id/baca/utama/2019/10/28/kemenkes-akan-memperkuat-fungsipreventif-dan-promotif-melalui-akreditasi-puskesmas/ [Accessed 10 Sep 2020].

40 Hoffmann T, Jansen J, Glasziou P. The importance and challenges of shared decision making in older people with multimorbidity. PLOS Med 2018;15:e1002530.

41 World Health Organization. Preliminary results: rapid assessment of service delivery for NCDS during the COVID-19 pandemic, 2020. Available: https://www.who.int/publications/m/item/rapidassessment-of-service-delivery-for-ncds-during-the-covid-19pandemic [Accessed 10 Sep 2020].

42 World Health Organization. Multimorbidity: technical series on safer primary care. Geneva, 2016.

43 Kernick D, Chew-Graham CA, O'Flynn N. Clinical assessment and management of multimorbidity: NICE guideline. $\mathrm{Br} J$ Gen Pract 2017;67:235-6.

44 Chandraratne NK, Pathirathna KGRV, Harrison C, et al. A comparison of policies and guidelines related to multimorbidity in the UK, Australia and Sri Lanka. Aust J Gen Pract 2018;47:15-19.

45 Wang X, Sun X, Birch S, et al. People-centred integrated care in urban China. Bull World Health Organ 2018;96:843-52.

46 Satibi S, Andayani TM, Endarti D, et al. Comparison of real cost versus the Indonesian case base groups (INA-CBGs) tariff rates among patients of high-incidence cancers under the National health insurance scheme. Asian Pac J Cancer Prev 2019;20:117-22.

47 Schröders J, Wall S, Hakimi M, et al. How is Indonesia coping with its epidemic of chronic noncommunicable diseases? A systematic review with meta-analysis. PLoS One 2017;12:e0179186.

48 Vellakkal S, Subramanian SV, Millett C, et al. Socioeconomic inequalities in non-communicable diseases prevalence in India: disparities between self-reported diagnoses and standardized measures. PLoS One 2013;8:e68219.

49 D'Hoore W, Bouckaert A, Tilquin C. Practical considerations on the use of the Charlson comorbidity index with administrative data bases. J Clin Epidemiol 1996;49:1429-33. 